\section{Revista de Literatura, História e Memória

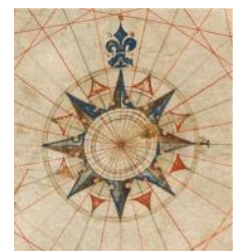 \\ Dossiê: Feminismos e literaturas \\ ISSN 1983-1498 \\ VOL. 17 - No 30 - 2021 \\ U N I O E S T E / CA S C A V E L - p. 128-145}

\title{
AS MULHERES DOS BECOS: A REPRESENTAÇÃO FEMININA EM BECOS DA MEMÓRIA, DE CONCEIÇÃO EVARISTO
}

The women of the alleys: the female representation in
Becos da memória, by Conceição Evaristo

Gabriela Soares Nogueira Andreatti ${ }^{1}$

RESUMO: O presente artigo analisa a representação das personagens femininas Ditinha, Mãe Joana, Dora e CidinhaCidoca, no romance Becos da Memória, de Conceição Evaristo. O foco da análise é demonstrar como a autora desconstrói os estereótipos que a literatura propagou, ao longo do tempo, da mulata como ser provocante e tentador, que envolvia os homens e, contudo, era desprovida da representação maternal. A análise teve como base a crítica literária feminista, demonstrando como as reivindicações desse movimento contribuíram para a mudança nas representações literárias, bem como a teoria pós-colonial que desvenda as estruturas de dominação impostas pelo homem branco. Unindo essas duas teorias, chegou-se à conclusão de que a representação das personagens femininas, que Evaristo realiza em sua obra, marca a singularidade de cada mulher.

PALAVRAS-CHAVE: Feminismo; Pós-Colonialismo; Representação Feminina; Conceição Evaristo.

ABSTRACT: This article analyzes the representation of the female characters Ditinha, Mãe Joana, Dora and Cidinha-Cidoca, in novel Becos da Memória, by Conceição Evaristo. The focus of this analysis is to demonstrate how the author deconstructs the stereotype "mulata" as being provocative and tempting, that seduces men and devoid of maternal representation that literature has propagated over time. The analysis was based on feminist literary criticism, demonstrating how the demands of the feminist movement contributed to the change in literary representations as well as post-colonial theory which studies the domination structures imposed by white men. According to these two theories, it was possible to conclude that the representation of the female characters, which Evaristo performs in her work, marks the uniqueness of each woman.

KEYWORDS: Feminism; Post-Colonialism; Female Representation; Conceição Evaristo.

\section{INTRODUÇÃO}

A literatura de autoria feminina, por muito tempo, permaneceu escondida sob a ótica de um cânone literário construído por uma cultura machista e patriarcal. A desestabilização desse paradigma só ocorreu após o advento da crítica feminista que passou a questionar a estrutura social e, consequentemente, a posição da mulher na literatura. Assim, mesmo que as conquistas obtidas pelo feminismo não garantiram a igualdade de gênero almejada pelas mulheres, essa luta fez emergir uma crítica literária feminista que, por volta de 1970, deu

\footnotetext{
${ }^{1}$ Aluna de Mestrado do Programa de Pós-Graduaçao em Letras, da Universidade Estadual de Maringá (UEM). Atua na área de pesquisa em Literatura e Construção de Identidades.
} 
destaque para uma gama de escritoras que haviam sido deixadas de fora da história literária, além de abrir a possibilidade para que novas escritoras conquistem seus lugares no cânone (ZOLIN, 2009a).

Dentro do que se pode chamar de panorama de uma literatura de autoria feminina, destaca-se a possibilidade de uma classificação das obras em três fases, de acordo com as perspectivas de representação feminina que carregam. Com base nos estudos de Showalter (1985 apud ZOLIN, 2009b), a literatura de autoria feminina segue as mesmas perspectivas das demais subculturas literárias, passando por fases de: imitação, protesto e autodescoberta; as quais ela denomina "feminina", para a fase de imitação da cultura machista e patriarcal; "feminista" para a fase de protesto e ruptura com os modelos anteriores; "fêmea", na qual há espaço para a autodescoberta e para a busca da identidade própria.

Na fase denominada "fêmea" (SHOWALTER apud ZOLIN, 2009b), os escritos de autoria feminina focam em trazer à tona temáticas relacionadas à identidade da mulher, abrindo a possibilidade de questionamentos acerca de problemáticas mais profundas sobre o tema. Nesse contexto, um dos possíveis assuntos que a luta feminista aborda são as questões raciais, que discutem o lugar da mulher negra dentro da sociedade e dentro do próprio movimento feminista. No que tange à literatura, essas questões passaram a enfatizar que as autoras negras encaram uma luta ainda maior para conquistar seu espaço no mercado editorial e no cânone literário, visto que precisam enfrentar o preconceito proveniente do sexismo e da raça.

Conceição Evaristo é uma das autoras contemporâneas que trava a difícil luta de reivindicar um lugar de destaque para a literatura afro-brasileira. A autora, que escreve desde a juventude, começou a publicar seus textos apenas aos quarenta e quatro anos, em 1990, quando participou da décima terceira edição dos Cadernos Negros, com a publicação de seis poemas.

A antologia Cadernos Negros foi criada em 1978 como um espaço no qual autores negros poderiam publicar seus escritos. A série, organizada pelo coletivo Quilombhoje, publica anualmente uma edição da obra, alternando seus volumes entre poemas e contos. Um dos motivos que levou à criação dos Cadernos foi a necessidade de um espaço em que os jovens negros pudessem expressar uma literatura que de fato os representasse "Porque faltou e falta ainda dentro dessa literatura brasileira feita por brancos os traços da nossa subjetividade. Nós estamos representados nessa literatura pela visão que o branco tem de nós" (CUTI apud COSTA, 2008, p. 23).

É essa vontade de ter uma literatura que de fato expresse a realidade do ser-negro que 
incentivou a criação da antologia e que também influenciou muitos negros a expressarem-se por meio da literatura. No que tange à expressão de uma literatura negra feminina, um dos casos mais conhecidos, no Brasil, é o de Carolina Maria de Jesus, no final da década de 60. Mulher negra, favelada e com pouca instrução escolar, ela utiliza a escrita como ferramenta para romper com a condição de subalternidade que a sociedade lhe impunha, retratando o negro e a sociedade não de uma perspectiva exterior, mas de quem vivencia os preconceitos no próprio corpo.

No mesmo viés, Evaristo (2005) defende o uso da literatura para denunciar a posição subalterna da mulher negra na sociedade, mais especificamente na sociedade brasileira. Por meio de seus textos, a autora mistura ficção e vivências de mulheres que sofrem com as injustiças sociais, para criar uma literatura capaz de renunciar aos estereótipos dominantes e apresentar a mulher negra em sua essência.

O presente artigo, nesse sentido, apresenta uma análise da forma como as personagens Ditinha, Mãe Joana, Cidinha-Cidoca e Dora são representadas na obra Becos da Memória (2018), de Conceição Evaristo, tendo como foco o estereótipo de mulher negra sensual. É graças às representações que "[...] são assinaladas e refletidas as relações do indivíduo com o mundo social" (ROSSINI, 2016 p. 100), ou seja, são elas que permitem averiguar os discursos perpetuados pela sociedade, bem como as relações de poder e dominação. Assim, a análise da representação das personagens femininas na obra Becos da Memória (2018), de Conceição Evaristo, tem como objetivo estudar de que forma a autora desconstrói os estereótipos literários que, por muito tempo, relegaram à figura da mulher negra a caracterização erotizada e estéril, quando desfrutava de sua sexualidade, e reprodutora quando caracterizada a serviço da casa grande.

\section{A REPRESENTAÇÃO DA MULHER NA LITERATURA}

O movimento feminista, já em com lideranças e objetivos mais estabelecidos, entrou no cenário político dos Estados Unidos e da Inglaterra em meados da segunda metade do século XIX com as campanhas que reivindicavam o sufrágio feminino e a igualdade política. Textos que versavam sobre os direitos das mulheres, no entanto, já eram produzidos desde o século XVIII, com autoras como: Mary Astell, Marie Olympe Gouges e Mary Wollstonecraft, que reivindicavam direitos civis e denunciavam a posição inferior ocupada pelas mulheres na sociedade (ZOLIN, 2009a).

De acordo com hooks, "Dito de maneira simples, feminismo é um movimento para 
acabar com sexismo, exploração sexista e opressão.” (2018, p. 17), ou seja, o feminismo busca a igualdade de direitos e deveres entre homens e mulheres, desnudando estruturas sociais por meio das quais essas últimas eram tratadas como seres inferiores, muitas das quais, reproduzidas pelas próprias mulheres. Como hooks (2018) enfatiza, o feminismo não é um movimento de mulheres contra homens, mas uma luta contra as estruturas sociais que reproduzem um sistema de controle feminino por meio do patriarcado que coloca o homem em posição de dominante e a mulher como objeto a ser dominado.

Quando o movimento começou a se estruturar, "Mulheres brancas com privilégio de classe rapidamente se declararam 'proprietárias' do movimento, colocando as mulheres brancas da classe trabalhadora, as brancas pobres e todas as mulheres não brancas na posição de seguidoras" (HOOKS, 2018, p. 58). As necessidades das mulheres negras, de outras etnias e de mulheres brancas da classe operária acabaram sendo relegadas ao esquecimento, fato que exigiu um redirecionamento das reivindicações da luta feminista, que passou a propor sua integração e igualdade social (HOOKS, 2018). No entanto, com a ascensão da terceira onda feminista e o direcionamento para questões de identidade, que visavam a acabar não só com o sexismo, mas com o racismo e com as diferenças sociais, passaram a ser foco das lutas feministas a igualdade de gênero e etnia. As atitudes "anti-homem” já não eram mais o foco e a sororidade ${ }^{2}$ passou a ser o lema defendido pelo movimento.

Semelhante interesse é reivindicado pelo discurso pós-colonial, que busca desvelar as estruturas de dominação impostas pelo imperialismo. Nesse sentido, pode-se fazer uma analogia entre a relação colonial ${ }^{3}$ e o patriarcalismo, no qual "Uma mulher da colônia é uma metáfora da mulher como colônia" (DU PLESSIS, 1985, p. 46 apud BONNICI, 2009, p. 266), ou seja, o movimento de domínio e abuso das terras ocupadas como colônias é semelhante ao abuso que mulheres sofrem, pois têm seus direitos e necessidades suprimidos em prol da vontade do dominador. Além disso, segundo Bonnici (2009), a mulher proveniente das sociedades coloniais é duplamente inferiorizada, pois sofre com o sexismo e, também, com o colonialismo.

Assim, esse redirecionamento do foco da luta feminista foi crucial para que houvesse a inclusão de causas raciais e de classe no movimento. Outra consequência foi a percepção da necessidade de se voltar para a representação que a literatura fazia das personagens femininas

\footnotetext{
${ }^{2}$ Com origem na palavra latina soror, que significa irmã, o conceito de sororidade diz respeito ao sentimento de partilha e de união entre as mulheres. No feminismo, o conceito veio estimular o apoio mútuo entre mulheres, que partilham os mesmos ideais e propósitos.

${ }^{3} \mathrm{O}$ colonialismo corresponde à extração de recursos e à exploração cultural, ocasionadas pela expansão europeia que ocorreu durante os últimos quinhentos anos (BONNICI, 2009).
} 
nos romances e o apagamento de escritoras ao longo dos séculos, que muitas vezes recorriam a pseudônimos masculinos para poderem publicar suas obras. Dessa forma, houve o desenvolvimento da crítica literária feminista, que direcionou o olhar das análises literárias para as autoras femininas, até então relegadas ao esquecimento, e para a forma como ocorria a representação das mulheres nos romances.

A pioneira nos estudos sobre a relação entre mulher e literatura foi a estadunidense Kate Millet, com a publicação de sua tese de doutorado Sexual Politics, em 1970. Como apresentado por Zolin (2009a), nessa obra, Millet questiona a postura patriarcal adotada pela sociedade em diversos assuntos, tais como educação, política e literatura. Nesse sistema, a mulher é condicionada ao homem, tratada como ser inferior, com base nas leis de um sistema rígido de papéis sexuais. As críticas de Millet questionaram, também, obras que propagavam os papéis femininos culturalmente ensinados como parte da natureza feminina, terminando por concordar com Beauvoir ao creditar à manifestação de poder o consentimento por parte do oprimido (ZOLIN, 2009a).

Segundo Beauvoir (1980), a definição do que é ser mulher se constrói a partir do que se é concebido como homem, em uma relação de alteridade. O "segundo sexo", mencionado no título de sua obra se refere à essa questão de a mulher ser tratada como o Outro na relação de alteridade, derivando do Um, homem, e por esse motivo sendo considerada inferior e submissa. Para ela, ainda, a mulher corrobora ao processo de dominação por reproduzir as estruturas de opressão difundidas pela cultura machista e patriarcal.

A tese de Millet, como apresentado por Zolin (2009a), expande o horizonte de uma leitura puramente focada no texto literário ao promover discussões que envolvam a relação direta entre a cultura e literatura "[...] acerca da posição secundária ocupada pelas heroínas dos romances de autoria masculina, como também pelas escritoras e críticas literárias." (ZOLIN, 2009a, p. 226), expondo como as personagens femininas e os próprios valores literários são controlados pelos homens. Nesse sentido, ela discute como obras canônicas representam a mulher com base em certos estereótipos culturais, como por exemplo: a mulher pura, incapaz e submissa; em oposição à mulher sedutora, perspicaz e imoral.

Assim como a tese de Millet apresenta que a representação que se faz da mulher nas narrativas é produto do pensamento vigente, Schwantes reforça esse pensamento ao afirmar: "Mas para escrever romances, um autor, independentemente de seu gênero, precisa criar personagens femininas, e essa criação vai derivar do conceito de feminilidade professado por 
sua sociedade.” (2010, p. 9). Tal perspectiva se insere no contexto de uma crítica pós-colonial ${ }^{4}$ que concebe os discursos como vinculados às manifestações ideológicas do período em que está inserido, revelando as relações de poder inscritas na sociedade (FOUCAULT, apud BONNICI, 2009). Desta forma, a representação das personagens em obras literárias ocorre conforme a posição política, social e ideológica do autor, visto que seu discurso é diretamente influenciado pelo pensamento vigente em seu contexto histórico.

A dominação exercida pelo homem branco não reverberou apenas sobre as mulheres; as chamadas minorias (judeus, negros, indígenas etc) também foram alvos de violência e opressão. Assim, no caso da produção de obras literárias, escritos que não fossem produzidos por homens brancos, héteros e de classe alta eram relegados à margem do cânone, acusados de não possuírem qualidade literária suficiente para serem reconhecidos pelo mercado editorial. No Brasil, a literatura foi dominada por essa padrão por muitos anos, sendo necessário que mulheres, negros, indígenas etc, tivessem de lutar pelo seu espaço junto ao mercado editorial e ao cânone.

Duarte (2010), em seu artigo "Por um conceito de literatura afro-brasileira", realiza um resgate histórico sobre a produção literária negra, no Brasil. Ele pontua algumas das principais produções afro-brasileiras, elencando características que permitam defini-las como tal e levantando discussões de obras como a série Cadernos Negros, responsável por uma valiosa contribuição para a formação e o desenvolvimento da literatura negra, na qual, segundo ele, "sobressai o tema do negro, enquanto individualidade e coletividade, inserção social e memória cultural" (DUARTE, 2010, p. 115). Além disso, o autor também destaca algumas formas de representação estereotipadas que negros e negras receberam ao longo do percurso literário "São estereótipos sociais largamente difundidos e assumidos inclusive entre suas vítimas, signos que funcionam como poderosos elementos de manutenção da desigualdade" (DUARTE, 2010, p. 131).

No que tange à representação feminina, as negras e mulatas integram o panorama literário brasileiro desde seu início. A representação estereotipada da mulher já é vista desde os primeiros contatos entre os brancos e as nativas brasileiras, os quais retratavam de forma erotizada os corpos e os comportamentos femininos (DUARTE, 2009). No decorrer do panorama literário, mulheres negras, pardas e mulatas continuaram a ser retratadas como objetos de desejo e da realização sexual masculina, geralmente, opostas às mulheres brancas, a quem cabia o estereótipo de boa esposa, conforme aponta Duarte (2009) ao utilizar como

\footnotetext{
${ }^{4}$ De acordo com Bonnici (2009), a crítica pós-colonial se encarrega de indagar as manifestações literárias e culturais de países afetados pelo processo imperial, desnudando seus efeitos sobre a literatura.
} 
exemplo as obras de Gregório de Matos, Manoel Antônio de Almeida, José de Alencar e Aluísio Azevedo

[...] a condição de corpo disponível vai marcar a figuração literária da mulata: animal erótico por excelência, desprovida de razão ou sensibilidade mais acuradas, confinada ao império dos sentidos e às artimanhas e trejeitos da sedução. Via de regra desgarrada da família, sem pai nem mãe, e destinada ao prazer isento de compromissos, a mulata construída pela literatura brasileira tem sua configuração marcada pelo signo da mulier fornicaria da tradição europeia, ser noturno e carnal, avatar da meretriz. Chama a atenção, em especial, o fato dessa representação, tão centrada no corpo de pele escura esculpido em cada detalhe para o prazer carnal, deixar visível em muitas de suas edições um sutil aleijão biológico: a infertilidade que, de modo sub-reptício, implica em abalar a própria ideia de afrodescendência (DUARTE, 2009, p. 6, 7).

A mulher mulata, portanto, era representada como o símbolo sexual dentro da literatura, sendo descrita como detentora de um corpo sensual, muitas vezes responsável por estimular o que havia de mais selvagem nos desejos masculinos, como no exemplo de Rita Baiana, em $O$ cortiço. Conforme Duarte (2009) destaca ao final do excerto, mesmo essas mulheres sendo descritas como sexualmente ativas, a gravidez e a maternidade eram ausentes dos relatos, negando a essas mulheres a representação destinada para as mulheres brancas, responsáveis pelo lar. A mulher negra, por sua vez, era destinada ao trabalho, era um corpo a ser explorado e, mesmo quando representada no papel de mãe, era também a ama de leite dos filhos do patrão ou a mulher parideira, diferentemente da representação romântica da maternidade branca.

Esse tipo de representação realça o corpo negro manchado pelo olhar do branco em sua posição de colonizador: "Os olhos do homem branco destroçam o corpo do homem negro e nesse ato de violência epistemológica seu próprio quadro de referência é transgredido, seu campo de visão perturbado" (BHABHA, 1998, p. 73). A forma como os brancos representaram os negros na literatura influenciou, por muito tempo, a própria representação que os negros faziam de si mesmos, de modo que para haver uma escrita que retratasse o negro sem o filtro do homem branco foi necessário romper os padrões vigentes. De forma análoga, a representação feminina, em uma primeira fase, reforçava os estereótipos machistas da literatura, sendo necessário passar por um processo de desconstrução para que isso fosse modificado.

Em contrapartida, autores e autoras negros começaram a questionar a representação dada a seus semelhantes na literatura e, em decorrência desse processo, surgem nas obras a representação da favela, dos subúrbios, das classes marginalizadas, críticas ao preconceito e 
denúncias que refletem as desigualdades sociais. No Brasil, os Cadernos negros, do coletivo Quilombhoje, foi um dos primeiros espaços que se preocupou em abordar uma literatura que não se submetesse aos estereótipos da representação feita pelo branco, garantindo que escritores negros e negras tivessem a possibilidade de publicar seus escritos. É nesse contexto que as obras de Conceição Evaristo podem ser descritas. Tendo como sua estreia a publicação de seis contos nos Cadernos, a autora se preocupa em trazer uma literatura que verse sobre a população negra e, principalmente, as desigualdades que acometem os moradores da favela e toda sorte de acontecimentos que cercam as vivências das personagens que daí surgem.

A escrita de Evaristo, segundo o que ela mesmo atesta, surge da mistura entre ficção e suas vivências enquanto mulher, negra e favelada. A "escrevivência" (EVARISTO, 2007), conceito cunhado pela autora, é o processo pelo qual as experiências de vida de autoras negras não podem ser desvinculadas da sua forma de escrita, de modo que o próprio conceito é uma junção das palavras escrita e vivência. Dessa forma, as obras da autora trazem suas experiências como parte fundamental da escrita e, mesmo que a ficção as tinja com outras cores, no cerne de seu fazer literário ainda apresenta o ser negro como esteio. Em suas palavras, "A escre(vivência) das mulheres negras explicita as aventuras e as desventuras de quem conhece uma dupla condição, que a sociedade teima em querer inferiorizada, mulher e negra" (EVARISTO, 2005), assim, não é uma escrita de quem observa de fora a vivência negra, mas de quem a sente em seu interior.

No processo de escrita de Becos da memória há o acúmulo de tudo o que significa ser mulher e negra no Brasil. Evaristo (2018) une sua voz à das demais mulheres que passaram por sua vida e, assim como ela, carregam o peso desse estigma social. Sua escrita é fruto dessas vozes, que se unem para denunciar os preconceitos e injustiças pelas quais passam diariamente, acarretando uma escrita marcada pela subjetividade da autora. Destarte, a escrita é uma das maneiras que faz possível ressignificar a forma como os negros e negras foram vistos pela sociedade durante séculos, isso porque essa escrita é responsável pela transmissão e perpetuação de estereótipos, de modo que apresentar uma escrita negra permite a desconstrução dos estereótipos propagados, nas palavras de Evaristo: “A nossa escrevivência não pode ser lida como histórias para 'ninar os da casa grande' e sim para incomodá-los em seus sonos injustos" (2007 p. 21).

\section{AS MULHERES DOS BECOS}

Em Becos da Memória (2018), Evaristo recorre à voz da narradora Maria-Nova para 
lhe ajudar no engenho de contar as histórias de sua infância. A aproximação entre autora e narradora advém da "escrevivência" com a qual Evaristo alimenta suas obras, transmitindo por meio da ficção as próprias experiências.

Quanto à parecença de Maria-Nova, comigo, no tempo do meu eu-menina, deixo a charada para quem nos ler resolver. Insinuo, apenas, que a literatura marcada por uma escrevivência pode con(fundir) a identidade da personagem narradora com a identidade da autora (EVARISTO, 2018, p. 12).

Maria-Nova narra a partir de uma perspectiva testemunhal as histórias que vivenciou enquanto criança, na favela. A menina, com seus treze anos, convive em meio à realidade de desigualdades sociais e raciais que afetam a vida dos moradores do lugar. Ela retrata histórias que viu e ouviu, de homens e mulheres, e com as quais aprendeu a realidade do estigma social que negros e pobres enfrentam no país.

Dentre as personagens do romance, diversas mulheres se destacam com suas histórias, suas dificuldades e lutas diárias para sustentar a família. As representações de Maria-Velha, Ditinha, Mãe Joana, Cidinha-Cidoca, Vó Rita, Dora, entre tantas outras que povoaram a infância da narradora, são construções que divergem das representações estereotipadas apresentadas pela literatura canônica. As personagens de Evaristo (2018) são retratadas pelo olhar da autora que, ao incorporar as próprias vivências em sua escrita, descreve de maneira singular as lutas e as adversidades que a condição de mulher e negra inflige às brasileiras.

Essas mulheres são marcadas pela condição de dupla inferioridade, sobre a qual comenta Evaristo (2005). No entanto, a representação que lhes confere a autora diverge dos estereótipos sexuais e raciais, por tanto tempo perpetuados na literatura. Cada uma das personagens é representada em sua individualidade, priorizando questões pessoais que perpassam os dilemas provenientes da condição social que ocupam. Além disso, diferentemente da esterilidade a que as negras eram submetidas anteriormente (DUARTE, 2009), a maternidade aparece como questão natural ao sexo feminino, tratada com todas as dificuldades que isso acarreta.

Muitas são as mães que povoam a narrativa de Becos da Memória (2018), Mãe Joana, Ditinha, Dora, Custódia, entre outras. A narradora volta sua atenção para o amor de Mãe Joana para com ela e com as demais filhas. Mesmo passando por dificuldades financeiras, Maria-Nova sabe que a mãe jamais seria capaz de vender ou entregar um de seus filhos, tal como em um dos relatos apresentados por ela na narrativa, em que devido às dificuldades financeiras, a mãe de Nazinha vendeu-a para um homem. O cuidado materno aparece como 
característica imanente da mulher, dona de muita beleza, mas que não sorria, ocupada entre a lavagem da roupa das patroas, na tina, e o cuidado de seus muitos filhos:

Maria-Nova tinha certeza, jamais Mãe Joana a venderia ou venderia algum de seus filhos. Ela comeria o pão que o diabo amassou, iria ao fundo do inferno, mataria se preciso fosse, mas não daria, nem venderia, nenhum dos filhos. Mãe Joana estava ali feito galinha arrepiada, detectando qualquer sinal de perigo. E na sua fragilidade enfrentava o mundo. Mãe Joana amamentava, criava e amava o que era seu. Maria-Nova sabia, Mãe Joana é mulher de poucas palavras. Mãe Joana é uma mulher de muito amor (EVARISTO, 2018, p. 31, 32).

O amor e cuidado maternais são destacados pela narradora durante a descrição da própria mãe. Ela ressalta a proteção que a mulher confere às crianças, enfrentando todas as dificuldades para criá-las. O romance apresenta, também, a importância que Mãe Joana dava à aprendizagem dos filhos, fazendo questão que todos aprendessem a ler. Nesse sentido a maternidade é destacada como ponto central na vida de Mãe Joana, sobressaindo-se às características sensuais que a literatura havia propagado, carregando o corpo negro de sensibilidade e afeto para com os filhos.

Além de Mãe Joana, a personagem Ditinha também tem a maternidade como uma de suas características. Com ela, todavia, a representação aborda a gravidez inesperada na adolescência e as dificuldades de sustentar sozinha o pai paralítico e os três filhos. A primeira gravidez de Ditinha ocorreu antes mesmo de ela ter quinze anos completos, mesmo com pouca idade, a menina já era órfã de mãe e responsável pelos cuidados da irmã mais nova. Ela engravida, ainda, outras duas vezes e em todas tenta provocar abortos, sem sucesso. Na quarta gravidez, Ditinha recorre a um aborto ilegal e sem estruturas, que acaba resultando em um processo de esterilidade.

A barriga de Ditinha cresceu. Beto estava com treze anos. Ela temia pelo futuro de Beto. E depois vieram o Zé, o Nico. A mesma coisa, ela só faltou tomar o diabo em pó para abortar, entretanto a barriga crescia. Na última gravidez, ela já sabendo que remédios, chás de nada adiantavam, pois tinha $o$ organismo forte, de mulher parideira, Ditinha foi mais longe. Maria Cosme não era escrupulosa como Vó Rita. Maria Cosme enfiou uma sonda por dentro de Ditinha. A sonda ficou lá dentro quase dez dias, até que numa manhã ela começou a sangrar. Sangrou tanto que foi parar no hospital. Os médicos queriam que ela dissesse o nome da "fazedeira de anjinhos". Ela não disse mesmo; pelo contrário, se preciso fosse, se pudesse, até esconder Maria Cosme, ela esconderia. Tiveram que retirar o útero e o ovário de Ditinha. Ela respirou aliviada, pelo menos não criaria barriga mais nunca (EVARISTO, 2018, p. 75).

A esterilidade acaba sendo encarada pela personagem como alívio por assegurar que 
ela não engravidaria mais e, consequentemente, não teria mais pessoas para alimentar. No entanto, essa medida é resultado de um ato desesperado, no qual a personagem arrisca a própria vida por uma questão que lhe deveria ser assistida por meios legais, caso a educação sexual, métodos anticoncepcionais e o aborto fossem assegurados pelos sistemas de saúde e de educação.

As questões referentes à educação sexual continuam sendo tabus para a sociedade, o que acarreta a gravidez indesejada de meninas que mal saíram da infância. Esse fato se torna ainda mais grave nas comunidades pobres, para as quais a informação e os meios de prevenção são mais escassos. hooks (2018) defende a liberdade sexual feminina amparada pela educação e pelo acesso aos meios de controle à natalidade, tais como métodos anticoncepcionais e o aborto. Conhecer o próprio corpo, ter acesso a meios seguros de controle de natalidade, garantem que a mulher assuma a autoridade sobre seu corpo e adquira a liberdade sexual, podendo decidir sobre quando e se deseja que a maternidade faça parte de sua vida.

A liberdade sexual da mulher exige controle de natalidade confiável e seguro. Sem isso, as mulheres não podem exercer total controle das consequências da atividade sexual. Mas a liberdade sexual da mulher também exige o conhecimento do corpo, a compreensão do significado de integridade sexual (HOOKS, 2018, p. 96).

A educação sexual e o conhecimento do próprio corpo são aspectos que, segundo hooks (2018), corroboram para a emancipação sexual das mulheres, isso porque o entendimento de seus processos fisiológicos permite a prevenção da gravidez indesejada e de doenças sexualmente transmissíveis. Ressalta-se que só o conhecimento não é suficiente para que mulheres assumam sua sexualidade de forma completa, mas é um passo importante nesse caminho. No romance, Dora é uma das personagens que se destaca por sua liberdade sexual. A mulher é descrita como uma mulata, alta, de voz e corpo melodiosos, que desde nova começou a descobrir os prazeres do corpo feminino. A representação de Dora, ainda que destaque a sensualidade, foca na mulher como dona do próprio corpo e de suas escolhas sexuais:

Realmente ela fora par de muitos homens pela vida e muitos homens haviam sido seu par. Tudo muito bom. Já nova, quando os seios eram apenas duas manchas mais escuras sobre a pele do peito, antes mesmo de eles crescerem embelezando-lhe o corpo, Dora já se permitia com os moleques de sua idade. Aprendeu cedo a deixar a passividade da mulher que só recebe a mão do homem sobre si e começou a vasculhar o corpo dos homens. Tocava com a mão e com a boca. Foi de muitos homens e muitos homens foram seus 
(EVARISTO, 2018, p. 68).

O destaque da sexualidade da personagem não suprime a possibilidade de uma gravidez. Depois de ter se relacionado uma vez com um homem que conhecera na casa dos patrões, Dora se descobre grávida. Contudo, a mulher não deseja a criança, de forma que após o parto entrega o filho aos cuidados do pai, sem interesse em manter contato. A ausência de afetividade entre mãe e filho é um ponto que o romance destaca quando Dora relata essa história a Nego Alírio. Pela voz do homem surge a reflexão e a crítica sobre a gravidez como um fardo que a mulher deve carregar:

Negro Alírio escutava a história de Dora, gostara da mulher. Não entendia o fato de se ter um filho e não criar apego. Se bem que ela até que tinha suas razões. Ele mesmo já deitara com tantas mulheres, só buscando o amor, só buscando o prazer. Filho quase sempre vem sem querer. E a mulher sempre carrega tudo. Carrega a barriga e as dificuldades. Ele nunca parara para pensar se alguma vez teria feito filho ou não. Também, se tivesse feito, a parceira na certa teria dito (EVARISTO, 2018, p. 69).

Nesse trecho, a afetividade entre mãe e filho tida como algo natural ao ser feminino é questionada, mostrando que a relação e o desejo maternal não são imanentes a todas as mulheres, de forma que muitas não se sentem atraídas por tal vínculo. $\mathrm{O}$ estranhamento do homem provém da ausência desse sentimento, mas ao mesmo tempo ele compara a própria relação com os possíveis filhos, os quais ele sequer sabe se existem. Por meio desse pensamento de Negro Alírio, a crítica à gravidez como fardo exclusivo da mulher é levantada, visto que a liberdade sexual feminina sempre esbarra na possibilidade de ser mãe.

A gravidez como fruto das relações sexuais é algo que contrasta com a representação das mulheres negras nos romances anteriores à revolução da crítica feminista. Segundo Duarte (2009), as negras e as mulatas eram retratadas na literatura como mulheres sensuais, entregues aos desejos sexuais e que seduziam os homens com sua beleza. No entanto, a maternidade lhes era negada nos romances, visto que seus corpos serviam apenas para satisfazer os desejos e não para a procriação. Tal representação passa a ser questionada:

O que se argumenta aqui é o que essa falta de representação materna para a mulher negra na literatura brasileira pode significar. Estaria a literatura, assim como a história, produzindo um apagamento ou destacando determinados aspectos em detrimento de outros, e assim ocultando os sentidos de uma matriz africana na sociedade brasileira? (EVARISTO, 2005, p. 3). 
O questionamento de Evaristo destaca o apagamento das raízes africanas nas terras brasileiras como uma das possíveis justificativas que levaram a literatura a produzir discursos em que imperasse a ausência da fertilidade das mulheres negras. A mãe África, que teve milhões de seus filhos roubados e trazidos para o país foi silenciada quando os romances desejavam apresentar a constituição do povo brasileiro. A retomada dessas raízes ocorre com o os movimentos que lutaram para que negros conquistassem seus direitos tanto na sociedade, quanto na literatura e na história de desenvolvimento do país.

Além de atuarem no papel de mães, as mulheres do romance trabalham como diaristas e lavadeiras para as famílias do bairro vizinho. As mulheres negras e periféricas demonstram sua força formando uma rede de trabalhadoras que atuam nos mais diversos campos de trabalho, em condições sub-humanas e por salários baixíssimos. Ao contrário das primeiras feministas brancas que lutavam pelo direito de conquistar um trabalho:

As mulheres negras não precisaram repetir o discurso da necessidade de romper com a prisão do lar e do direito ao trabalho, pois elas sempre trabalharam desde a escravidão, inclusive nas ruas, como as escravas de ganho. E com a Abolição confirmaram o papel de provedoras material e espiritual da comunidade afro-descendente (sic) quando o homem negro ficou mais vulnerável às transformações sociais da época (EVARISTO, 2005 , p. 4, grifos da autora).

O trabalho, que foi visto como chave para a libertação das mulheres da opressão sexista durante a primeira e segunda onda feminista, não constituía uma conquista de direito para as mulheres negras e de classes de baixa renda, visto que essas já atuavam no mercado de trabalho. O fato de já serem assalariadas fez com que muitas feministas assegurassem que essas mulheres “já eram livres" (HOOKS, 2018, p. 63), todavia, o sexismo continuava a oprimi-las, concedendo-lhes menores salários, condições exaustivas e abusos, agravados no caso das trabalhadoras negras. Assim, uma suposta liberdade alcançada com o trabalho não condizia com a realidade de muitas mulheres que já trabalhavam desde de antes do início do movimento, subordinadas à exaustão em trabalhos precários e, em muitos casos, ainda eram responsáveis por suprir as necessidades dos filhos sozinhas.

Vale ressaltar que a atribuição da força de trabalho às mulheres negras recai em outro estereótipo, o de que elas são fisicamente mais fortes e por isso suportam trabalhos braçais com melhor desempenho. Os "Estereótipos racistas, como o da mulher negra de força sobrehumana, são mitos que povoam a mente de muitas mulheres brancas, o que permite que elas ignorem até que ponto as mulheres negras são vítimas em potencial dessa sociedade [...]” 
(HOOKS, 2019, p. 44), ou seja, a crença de que elas são mais resistentes levou essas mulheres a serem condenadas a trabalhos extenuantes e que as colocavam e condições sub-humanas. Nos romances brasileiros, muitas são as representações das mulheres negras em trabalhos pesados, principalmente enquanto lavadeiras, que esfregavam roupas de sol a sol e carregavam baldes pesados de água para encher suas tinas, como nos romances $O$ cortiço, de Aluízio Azevedo, Quarto de despejo, de Carolina Maria de Jesus e no próprio romance analisado neste trabalho.

Assim, o trabalho braçal é o meio pelo qual as mulheres conseguem garantir a sobrevivência da família, mesmo que para isso enfrentem jornadas exaustivas. Em Becos da memória (2018), Ditinha trabalha como empregada doméstica na casa de Dona Laura, uma moça branca e de classe alta. Ela realiza as atividades na casa, enquanto tece relações entre sua realidade e a da patroa. A diferença social é apresentada por meio de um monólogo, no qual Ditinha sequer consegue se imaginar na posição ocupada por Dona Laura:

\begin{abstract}
"Será que eu gostaria de ter umas joias dessas? Também, se tivesse, não teria vestidos e sapatos que combinassem. E se eu tivesse vestidos e sapatos que combinassem, não saberia como arrumar meus cabelos." Olhou-se no espelho e sentiu-se tão feia, mais feia do que normalmente se sentia. "E se eu tivesse vestidos e sapatos e soubesse arrumar os meus cabelos? (Ditinha detestava o cabelo dela.) Mesmo assim eu não assentaria com essas joias" (EVARISTO, 2018, p. 73).
\end{abstract}

O desejo de se ver adornada pelos pertences de Dona Laura, de desfrutar dos prazeres que aquela desfruta, são barrados pelo sentimento de inferioridade que Ditinha possui em relação a sua aparência e a condição social. A incapacidade de imaginar demonstra como ela propaga a relação de dominação existente na sociedade, atendo-se, principalmente, a estereótipos de beleza. Esse discurso demonstra como a ausência de imagens fora dos padrões na mídia pode afetar negativamente a capacidade de empoderamento de mulheres, isso porque elas acabam ficando presas a padrões tidos como o único existente e, dessa forma, desvalorizando a si mesmas. Ditinha detesta o próprio cabelo, não gosta da aparência que vê no espelho, tendo seu julgamento estético baseado naquilo que a sociedade transmite como sendo belo: "Olhando e admirando a beleza de Dona Laura, Ditinha se sentiu mais feia ainda. Baixou os olhos envergonhada de si mesma." (EVARISTO, 2018, p. 74)

Muito alta, loira e de olhos verdes, os adjetivos utilizados para definir a patroa reforçam o estereótipo de beleza europeu, os quais são defendidos pela indústria capitalista que propaga uma noção racista e sexista de beleza. Ditinha não aceita os cabelos crespos e sua beleza negra, não gosta do que vê no espelho, mas admira a beleza da patroa que segue os 
padrões difundidos pela mídia. Hooks (2018) assinala a problemática dessa padronização da beleza, que muito se deve a questões mercadológicas:

Certamente era do interesse da indústria de moda e cosméticos capitalista patriarcal de supremacia branca "glamorizar novamente" as noções sexistas de beleza. A mídia de massa seguiu esses passos. Em filmes, na televisão e em anúncios públicos, imagens de mulheres magrelas, de cabelos pintados de loiro e com aparência de quem mataria por uma bela refeição tornou-se a norma (HOOKS, 2018, p. 48).

Nesse sentido, a mídia e a indústria são responsáveis por reafirmar estruturas baseadas em padrões machistas e racistas que elegem a mulher branca como ícone de beleza. Além disso, a relação de submissão que existe entre ambas é ressaltada na afirmação "Ditinha gostava muito de D. Laura e D. Laura gostava muito do trabalho de Ditinha" (EVARISTO, 2018, p. 74), por meio da qual é possível notar que a patroa não compartilha o mesmo tipo de sentimento que a empregada. Para aquela, Ditinha era vista por seu trabalho, despersonalizada de sua sensibilidade em prol da mão de obra que realiza.

O trabalho de empregada, no entanto, não surge para Ditinha como motivo de vergonha, ela recorre a isso como forma de evitar os pensamentos que lhe perturbam. $\mathrm{O}$ esforço físico ajuda a mulher a não refletir sobre as desigualdades sociais e ameniza o sofrimento. Além disso, ela assume o papel de doméstica como parte de sua identidade, sabe que realiza o trabalho bem e não aceita quando os policiais a chamam de "falsa doméstica", ao qual ela retruca "Não, moço, falsa doméstica eu não sou, não!” (EVARISTO, 2018, p. 90).

A beleza das mulheres retratadas por Evaristo (2018) se dá por meio de suas individualidades, as descrições não se restringem aos estereótipos de beleza sensualizada e aos corpos atraentes. A descrição sensual e o comportamento provocante de Cidinha-Cidoca, com seu corpo negro sombreando um vestido branco e solto e seu "rabo de ouro", como era conhecida, diferem daquele reproduzido nas narrativas canônicas. Ela não é desprovida de sua individualidade, a narradora chama a atenção para o comportamento que tomara conta da mulher, "Bonita a mulher, mesmo com aqueles olhos parados e com aquela carapinha de doida! Bonita a mulher! Doida mansa, muito mansa" (EVARISTO, 2018, p. 18).

Cidinha- Cidoca, tida como motivo de orgulho, conhecida pelos moradores dali e de outras favelas, andava desanimada e quieta. A narradora destaca o caráter reflexivo que havia tomado conta da mulher, a qual perdera o interesse na vida "E sua fala era uma resolução de morte. Ela dizia que iria morrer. Morrer como, por quê, e de quê, perguntaram para ela. A moça respondia que ia morrer de não viver" (EVARISTO, 2018, p. 113). Sua beleza dá lugar 
ao silêncio, a personagem se torna a própria resolução de morte; um corpo que outrora era a própria definição de vida, de sensualidade, de calor, perde sua vontade de viver ao verem desocupar sua terra. Não há uma explicação concreta do que leva a mulher a perder o interesse pela vida, contudo, a narradora destaca como a personagem era motivo de orgulho dos homens da favela e como essa vivacidade entra em declínio com a proximidade do fim do lugar, de modo que há a possibilidade de se comparar a mulher à própria favela.

A beleza é característica destacada, também, em outras personagens. Dora, como já fora mencionado, é uma mulata alta e envolvente; Mãe Joana é caracterizada pela sua beleza e pela ausência de sorrisos; Cidinha-Cidoca, com o corpo sensual e desejada pelos homens. Cada uma das mulheres de Becos da memória (2018) carrega a beleza e a sensualidade sem, contudo, perder a personalidade individual, evidenciada, entre outros, pela exposição do caráter psicológico das personagens, que torna cada mulher uma construção singular.

\section{CONSIDERAÇÕES FINAIS}

A representação feminina que Evaristo (2018) realiza em sua obra diverge dos estereótipos amplamente propagados pela literatura canônica até por volta dos anos 1960 . Vozes destoantes já podiam ser ouvidas em meio ao discurso majoritariamente racista e patriarcal que era difundido na representação feminina, todavia a crescente luta pelos direitos das mulheres, suas conquistas, a ocupação de cargos empresariais mais importantes, a maior representação política, bem como a mudança no foco dos estudos feministas, o surgimento dos estudos pós-coloniais, o entendimento do saber em sua relação direta com o poder são alguns dos motivos que permitiram o questionamento e o surgimento de novas formas de conhecimento e de discurso no meio literário.

Uma vez que a escrita da autora é marcada pela própria vivência, pela experiência de mulher, negra e favelada, a construção de suas personagens em Becos da Memória (2018) consegue abranger em diversas perspectivas o que é ser mulher e negra, no Brasil. As personagens da obra são construídas em perspectivas individuais, que realçam as singularidades em suas personalidades, fugindo aos estereótipos que marcaram as negras e as mulatas como objetos sexuais. A esterilidade deixa de ser imposta às personagens e a maternidade manifesta-se de variadas formas no texto de Evaristo (2018). A relação de amor e proteção, o medo e os problemas da gravidez indesejada e a quebra do discurso do desejo de maternidade como algo imanente às mulheres são questões e problemáticas que se tornam objeto de representação na obra da autora. 
Além da maternidade, a autora problematiza questões de beleza que perduram na sociedade. Tanto o estereótipo da mulata sensual, quanto o padrão de beleza europeu são abordados no romance, por meio de um discurso que questiona essas construções como únicos padrões possíveis a serem seguidos. Por meio do monólogo de Ditinha, a autora demonstra como essa representação padronizada fere a autoestima de mulheres que não se veem nas mídias, possibilitando que se discuta a necessidade da inserção de novas formas de beleza.

Ao construir essa gama plural de mulheres em seu romance, Evaristo (2018) apresenta um novo olhar sobre a caracterização do negro na literatura brasileira, um olhar que começou a ser mais difundido com as publicações do coletivo Quilombhoje e que vem ganhando cada vez mais espaço em meio à mídia nacional e internacional, com a publicação de mais autores negros e negras, como as própria obras de Conceição Evaristo, Djamila Ribeiro, Sueli Carneiro, além do o relançamento de obras fundamentais para a construção da identidade da literatura negra, por exemplo o projeto da editora Companhia das Letras que, recentemente, relançou Casa de Alvenaria, de Carolina Maria de Jesus.

\section{REFERÊNCIAS}

BEAUVOIR, Simone de. O segundo sexo. Tradução Sérgio Millet. Rio de Janeiro: Nova Fronteira, 1980.

BHABHA, Homi K. Interrogando a Identidade: Frantz Fanon e a prerrogativa pós-colonial. In: O Local da Cultura. Trad. Myrian Ávila; Eliana Lourenço de Lima Reis; Gláucia Renate Gonçalves. Belo Horizonte: Editora UFMG, 1998. p. 70 - 104.

BONNICI, Thomas. Teoria e Crítica Pós-Colonialista. In: BONNICI, Thomas e ZOLIN, Lúcia Osana (Orgs.). Teoria Literária. 3. ed. Ver. Ampl. Maringá: EDUEM, 2009, p. 257 286.

Cadernos Negros, n ${ }^{\circ}$. São Paulo: Edição dos Autores, 1978.

COSTA, Aline. Um pouco de história de cadernos negros. In: Cadernos Negros: Três décadas. São Paulo: Quilombhoje, 2008. p. 19-39.

DUARTE, Eduardo de Assis. Literatura afro-brasileira: um conceito em construção. Estudos de Literatura Brasileira Contemporânea, Brasília, n. 31, p. 11-23, jan. Juun. 2008. $\overline{138,2010 .}$

Por um conceito de literatura afro-brasileira. Terceira Margem, v. 14, n. 23, p. 113. Mulheres marcadas: literatura, gênero, etnicidade. Terra Roxa e Outras Terras: 
Revista de Estudos Literários. v. 17-A. dez. 2009, p. 6 - 18.

EVARISTO, Conceição. Becos da Memória. 3. ed. Rio de Janeiro: Pallas, 2018. ePUB.

Gênero e Etnia: uma escre(vivência) de dupla face. Nadilza Martins de Barros Moreira \& Liane Schneider (orgs). Mulheres no Mundo: Etnia, Marginalidade e Diáspora, João Pessoa, UFPB, Idéia/Editora Universitária, 2005.

EVARISTO, Conceição. Da grafia-desenho de minha mãe, um dos lugares de nascimento de minha escrita. In: ALEXANDRE, Marcos Antônio (org). Representações performáticas brasileiras: teorias, práticas e suas interfaces. Belo Horizonte: Mazza Edições, 2007.

HOOKS, Bell. O feminismo é para todo mundo: políticas arrebatadoras. trad Ana Luiza Libânio. - 1. ed. - Rio de Janeiro: Rosa dos Tempos, 2018. [versão digital].

Teoria Feminista: da margem ao centro. trad. Rainer Patriota. São Paulo: Perspectiva, 2019.

MILLET, Kate. Política sexual. Trad. Alice Sampaio, Gisela da Conceição e Manuela Torres. Lisboa: Publicações Dom Quixote, 1974.

ROSSINI, Tayza Nogueira. A construção do feminino na literatura: representando a diferença. Trem de Letras, Minas Gerais, v. 3, n. 1, p. 97-111, 2016.

SCHWANTES, Cíntia. Dilemas da representação feminina. DOI10.5216/o. v6i1.9308. OPSIS, v. 6, n. 1, p. 07-19, 27 mar. 2010.

ZOLIN, Lúcia Osana. Crítica Feminista. In: BONNICI, Thomas e ZOLIN, Lúcia Osana (Orgs.). Teoria Literária. 3. ed. Ver. Ampl. Maringá: EDUEM, 2009a, p. 217 - 242.

ZOLIN, Lúcia Osana. Literatura de Autoria Feminina. In: BONNICI, Thomas e ZOLIN, Lúcia Osana (Orgs.). Teoria Literária. 3. ed. Ver. Ampl. Maringá: EDUEM, 2009b, p. 327 336. 